these just offering vague metaphors of untested relevance? Indeed, if I have a criticism of Miller and Page, it is that they don't sufficiently address the fearsome question of how such testing might be done. This is discussed in some detail in Scott de Marchi's Computational and Mathematical Modeling in the Social Sciences (Cambridge Univ. Press, 2005). But in any event, that isn't really the point. Shapiro suggests that the role of political theorists is to rove the political landscape "debunking myths and misunderstandings that shape political practice". Properly applied, ABM might do just that.

The famous segregation model of economist Thomas Schelling, who pioneered the
ABM approach in the 1970s, showed that a high degree of social segregation does not, as one might assume, imply extreme intolerance. Conversely, and relevant to today's political climate, it showed that a combination of mobility and choice may amplify marginal preferences or imbalances into major social divisions. Agentbased models may not describe reality, but they can show how interaction and nonlinearity produce social outcomes that could not be predicted simply by inspecting the behavioural rules. They undermine the common political presumption that group behaviour is a multiplied version of individual behaviour. They expose how ideas such as market efficiency may mutate from predictions of simplistic theories into dogmas that are applied insistently to the real economy. They might not tell us why certain social phenomena happen, but they offer mechanisms for how they might.

The challenge, which cannot be over-emphasized, is to ensure that $\mathrm{ABM}$ does not get above its station. It is a tool, not just another method for imprinting belief and prejudice with the false authority of 'theory'. As such, these models could form part of a toolbox that helps social scientists to re-engage with reality rather than trying to reinvent it.

Philip Ball is author of Critical Mass and a consultant editor for Nature.

\title{
In the eye of the storm
}

\section{Storm World: Hurricanes, Politics, and the Battle Over Global Warming \\ by Chris Mooney \\ Harcourt: July 2007. 392 pp. \$26}

\section{James Elsner}

Chris Mooney's follow-up to his The Republican War on Science (Basic Books, 2005) is a reconnaissance flight into the turbulent debate over a link between hurricane activity and global warming. The flight log is compelling enough for Hollywood. It records a clash between the empiricist climate scientist William Gray (think Ian McKellen) at Colorado State University and the theoretician Kerry Emanuel (think Tom Hanks) at the Massachusetts Institute of Technology. Journalist Mooney has a scriptwriter's flair for pitting his protagonists against each other and dishing the historical and methodological back story in vivid prose: "If we're really making the deadliest storms on Earth still deadlier, it will represent one of humanity's all-time greatest foot-shooting episodes."

The debate swirls about the cause of the

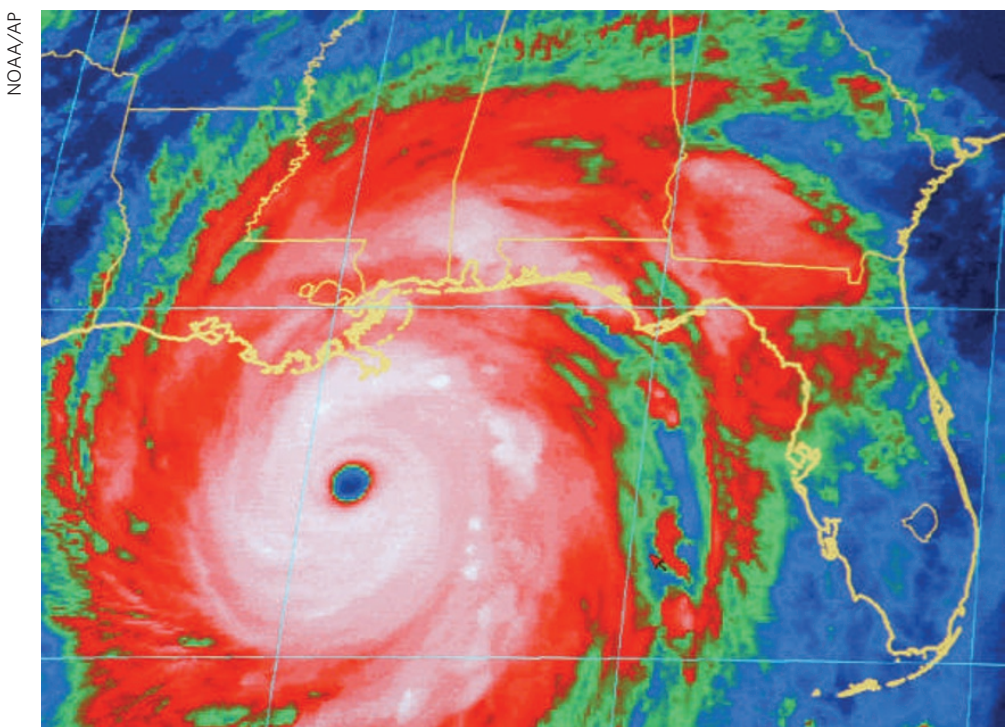

recent upswing in severe hurricanes, especially over the Atlantic where evidence for a change is most compelling. Warmer tropical oceans will increase the potential intensity of tropical cyclones, but for Gray the causal chain ends with the ocean. "Nobody knows how the atmosphere works," he says, feeling that it is far too complicated to be captured by a computer. Emanuel, on the other hand, adds a further link to the chain, placing the blame on human meddling with the composition of the atmosphere.

Just a month before Hurricane Katrina's devastating strike on America's south coast on 29 August 2005, Emanuel published a paper in this journal (Nature 436, 686-688; 2005) that ignited a scientific debate by linking storm strength to ocean temperatures. It also triggered a maelstrom of media coverage that resulted in the US National Oceanic and Atmospheric Administration (NOAA) closing ranks and claiming unequivocally that the increase in Atlantic hurricane activity since 1995 could be attributed solely to an ocean cycle unrelated to greenhouse warming. Mooney is at his best when describing

Debate swirls about the recent upswing in severe hurricanes such as Katrina. this sort of political tempest. By allowing what Emanuel calls the "party line" while discouraging dissenters, NOAA was, in Mooney's words, "gaming the release of information and trying to shift the debate in their favoured direction".

Mooney revisits his call, propounded in his earlier book and in subsequent newspaper and magazine columns, for scientists to do a better job of communicating science to the public and media. He urges researchers to stop pretending that they are nothing but objective "fact machines" and to instead give more general interpretations of their results and put them into a broader context.

Drawing on scientific conferences and on interviews with hurricane and climate scientists during 2006, Mooney covers plenty of ground, from heat engines and synoptic meteorology to computer modelling, and all without equations. At times Storm World feels hurried, US-centric and somewhat uneven, jumping between history, science and politics. But Mooney presents an accurate account of the clash between two of the most prominent climate scientists today. He is a good writer "Scientists, like hurricanes, do extraordinary things at high wind speeds" - and his stories are consistently about people, giving the book a wide appeal.

In the end, he does give a clear picture of what the hurricane-climate change debate is about and where it might go next. As there are no answers, the book provides none. Not surprisingly, Mooney takes a liking to Gray, but cannot recommend his view that global warming has nothing to do with hurricane activity. Amusingly, Mooney also implies that, for storm climatologists, science sometimes plays second fiddle to entertaining soundbites.

Many scientists are contributing to one of the most important climate debates in history. Neither side is completely wrong and both would do well to study the full breadth of literature, to which Storm World is a useful addition. It's a great summer read, while the story continues. Let's hope there are more answers in the sequel.

James Elsner is a professor of geography at Florida State University, Tallahassee, Florida 32306, USA. 